\title{
A RECENT UPDATE ON HISTOGENESIS OF ADENOMATOID ODONTOGENIC TUMOR: A REVIEW
}

\author{
SAHANAZ P AHMED*, NANDAKUMAR ARULMOZHI, RAMADAS RAMYA, KRISHNAKUMAR KARUNYA
}

Department of Oral and Maxillofacial Pathology, SRM Dental College, Chennai, Tamil Nadu, India. Email: sahanaz.praveen87@gmail.com

Received: 13 July 2018, Revised and Accepted: 22 October 2018

\begin{abstract}
Adenomatoid odontogenic tumor (AOT) is a relatively rare benign, epithelial tumor of odontogenic origin. There is varying class of thoughts contemplating this lesion to be a hamartoma or neoplastic growth of odontogenic epithelium. Controversy regarding the histogenesis of the lesion is plentiful in earlier literature. The recent advent of immunohistochemical and ultrastructural studies has aided in throwing light on the tissue of origin of this tumor. This review aims at understanding the evolving concepts of histogenesis of AOT to better understand the biological behavior of the lesion. The review of AOT was carried out using PubMed and Google Scholar databases and 39 articles from the year 2001 to 2016 which contributed to the histogenesis of AOT were included for review. Since the origin of the cystic lining is similar to a reduced enamel epithelium and not the dental lamina, we propose the former to be the progenitor of AOT. Furthermore, we consider extra-follicular, as well as peripheral AOTs, originate from the remnants of Hertwig's epithelial root sheath (epithelial rests of Malassez), which complies with the common histology for all these variants.
\end{abstract}

Keywords: Adenomatoid odontogenic tumor, Odontogenic tumor, Histogenesis.

(C) 2019 The Authors. Published by Innovare Academic Sciences Pvt Ltd. This is an open access article under the CC BY license (http://creativecommons. org/licenses/by/4. 0/) DOI: http://dx.doi.org/10.22159/ajpcr.2019.v12i2.28452

\section{INTRODUCTION}

Odontogenic tumors are defined as a spectrum of lesions ranging from benign and malignant neoplasms to dental hamartomas; formed generally in the same sequence as in normal tooth development and all arising from dental remnants, that is, derived either from epithelial, ectomesenchymal and/or mesenchymal elements of the toothforming apparatus [1]. Knowledge of the basic elementary characters of different odontogenic tumors such as site of occurrence, age distribution and radiographic appearance is important in arriving at a clinical differential diagnosis [2,3]. Odontogenic tumors like any other neoplasm can mimic its cell of origin histologically $[2,4]$. The epithelium contributing to odontogenic tumor may be derived from the pre/post functional dental lamina, basal cell layer of the gingival epithelium, dental papilla/follicle, and remnants in the periodontal ligaments $[5,6]$.

Adenomatoid odontogenic tumor (AOT) is a relatively rare, deviant, hamartomatous, benign, epithelial lesion of odontogenic origin [7], and constitutes about $2-7 \%$ of odontogenic cysts and tumors combined [5]. The WHO classification of odontogenic tumors has defined AOT as being comprised of odontogenic epithelium in an array of histoarchitectural patterns, embedded in mature connective tissue stroma, and characterized by gradual but progressive growth [8] with generally no tendency of recurrence. AOT is generally intraosseous, primarily in the anterior maxilla; the lower and upper canine area has more affinity to this lesion; however, it can also be seen in peripheral locations. More commonly seen in young patients, females are affected twice as commonly as males with a ratio of 1:1.9 [9]. AOT is a non-invasive tumor and recurrence rate is very low [10]. Different types or variants of AOT are central (or intraosseous) variants which are further divided into follicular (or pericoronal) type and extrafollicular (or extracoronal) type and the peripheral (or gingival) variant (PAOT) [11]. AOT could remain intraosseous or peripheral in the jaw bones, depending on the spatial position of the tumor and associated tooth. In deeper impacted teeth, there would be more possibility of AOT to be intraosseous follicular or extrafollicular (in the case of tooth eruption) lesion. In tooth impactions next to the alveolar ridge, the tumor could occasionally involve the gingiva during or after the eruption process, which would justify the peripheral variant $[12,13]$.

The review of AOT was carried out using PubMed and Google Scholar databases. The keywords used were (AOT, histogenesis, odontogenic tumors, and histology) and all articles were taken for initial evaluation. Review articles on AOT and case reports on other odontogenictumors other than AOT were excluded from the search. We also excluded clinical trials and animal research. In the present review, we studied the following 39 articles from the year 2001 to 2016 which contributed to the histogenesis of AOT were included for review (Table 1) [8,12,14-19,25-32,35-51]. The earlier articles were excluded since no significant research on histogenesis was available before this year, and earlier concepts were already addressed in articles included for this study. The purpose of this review was to delineate the clinical, histopathological, and immunohistochemical (IHC) profile of AOT to aid its diagnosis and alleviate confusion between other tumors in this category.

There are legitimate reasons for characterizing and renaming an entity, and foremost among these is when it can be established that it behaves and can be managed differently from other members of its original group. In most cases, it will be recognized as having distinguishable histopathological features also [33]. Thus, it becomes a new clinicopathological entity. The extensive review of literature of AOT has been enlisted in Table 1. This was how the AOT emerged from the then variants of ameloblastomas [34]

\section{WHY AOT WAS CLASSIFIED AS EPITHELIAL TUMOR?}

Based on the classification of odontogenic tumors that are based on the inductive influences between epithelial and mesenchymal tissues during odontogenesis, AOT has been included in the epithelial category rather than the mixed group, despite the presence of abnormal hard tissue elements within the tumor [52,53]. This was supported in a recent IHC study that used bone morphogenetic protein (BMP) to divide odontogenic tumors into those that were purely epithelial (i.e., negative for BMP) and those that formed hard tissue (i.e., positive for BMP) [54]. The epithelial component of this tumor is cellular where the pre-ameloblast like cells are arranged radially with interspersing spindle-shaped cells in some areas, whereas the other areas show epithelial cells which are arranged in interlacing strands resembling that of plexiform ameloblastomas [55,56].

\section{Hamartoma or neoplasm}

There is two class of thought, while some contemplate this lesion as a developmental outgrowth or hamartoma, other groups account them 


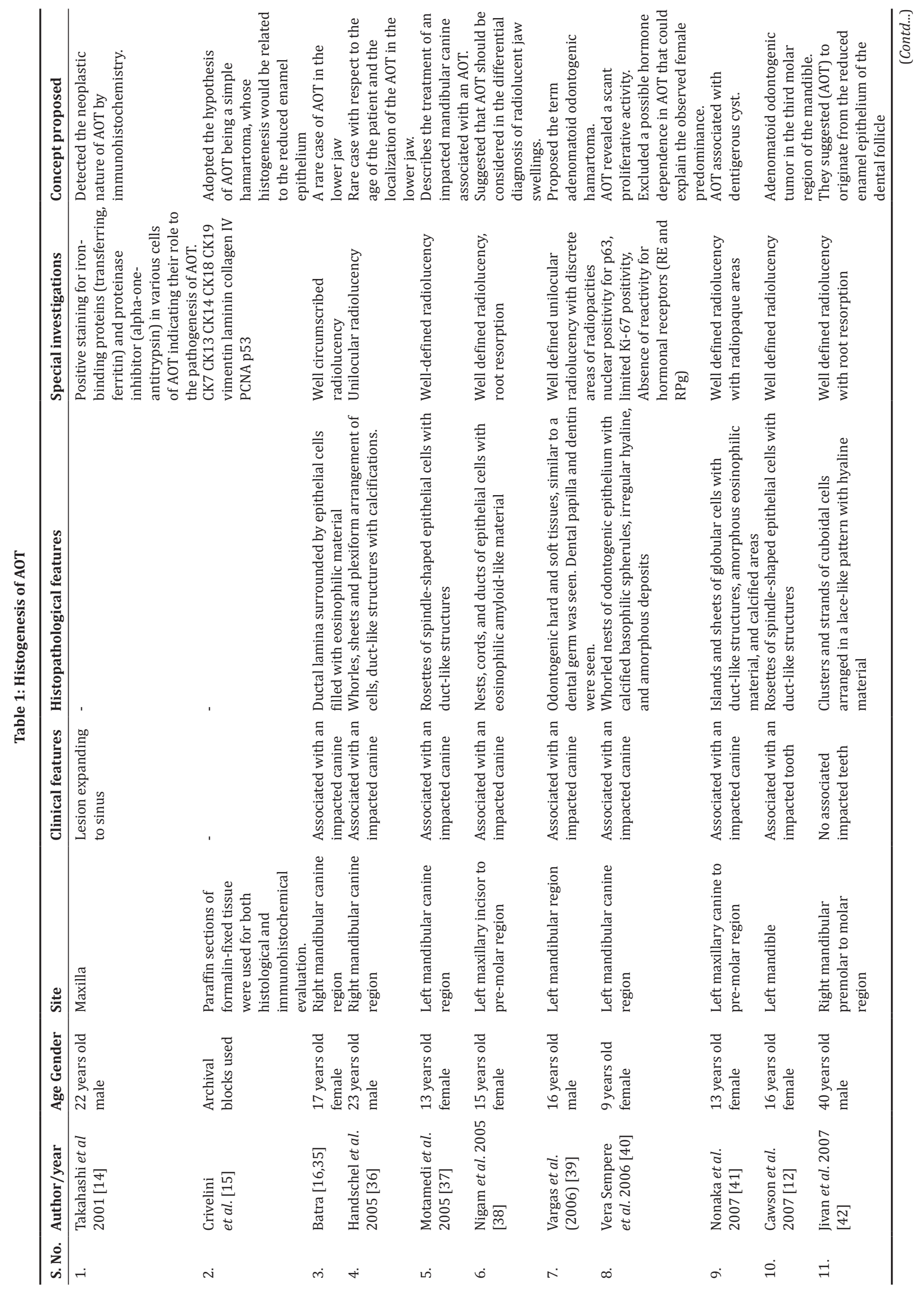




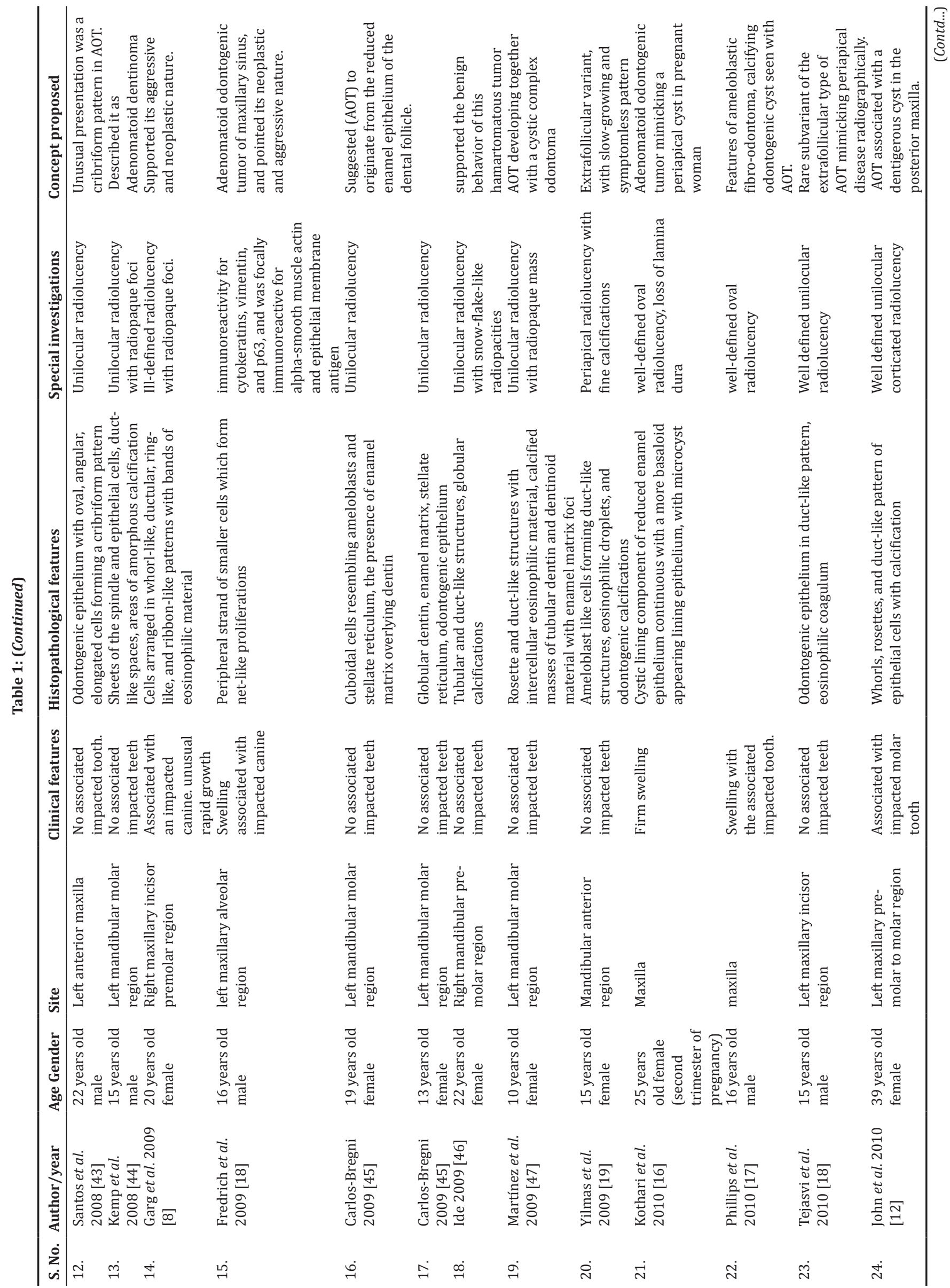




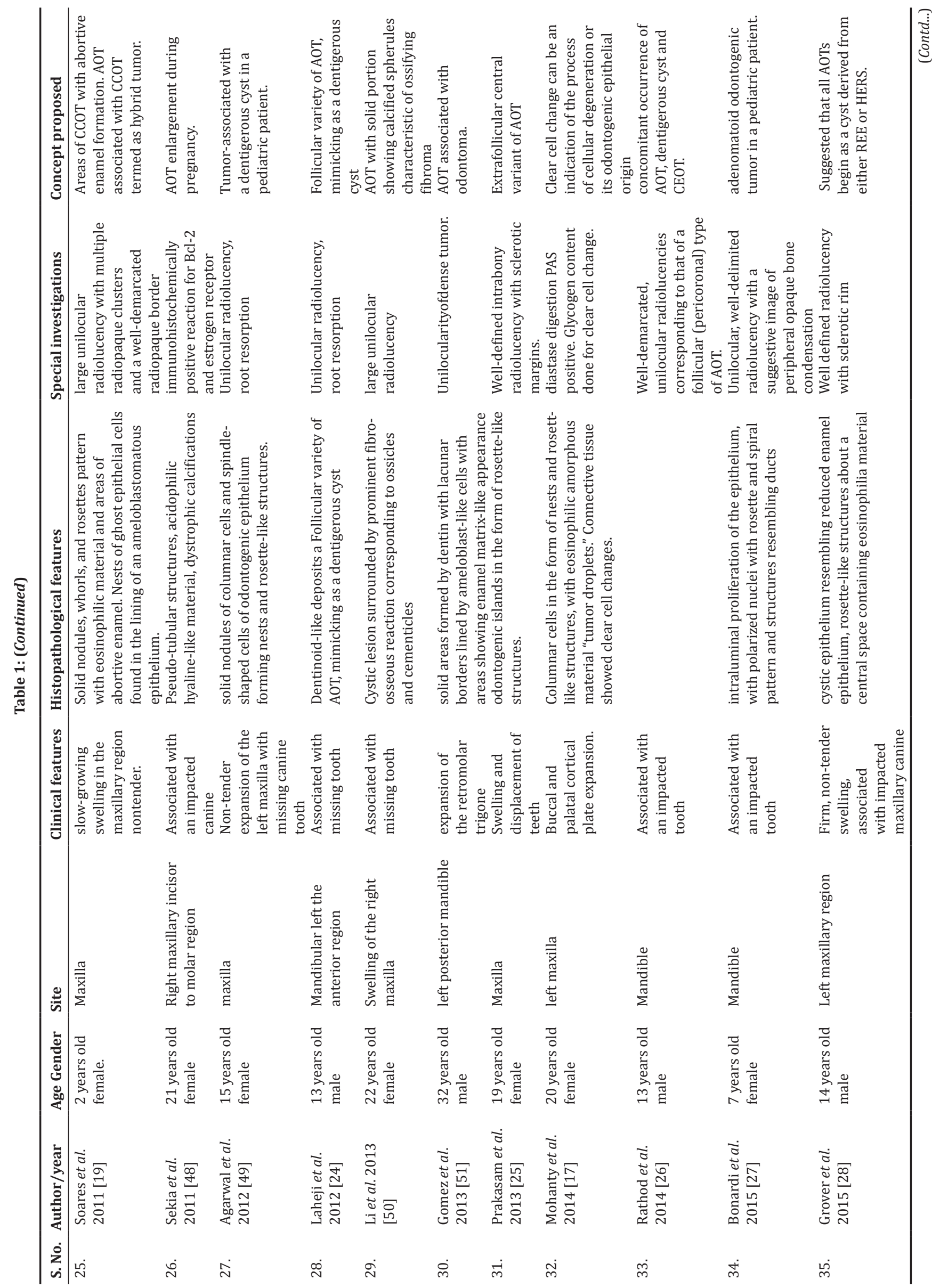




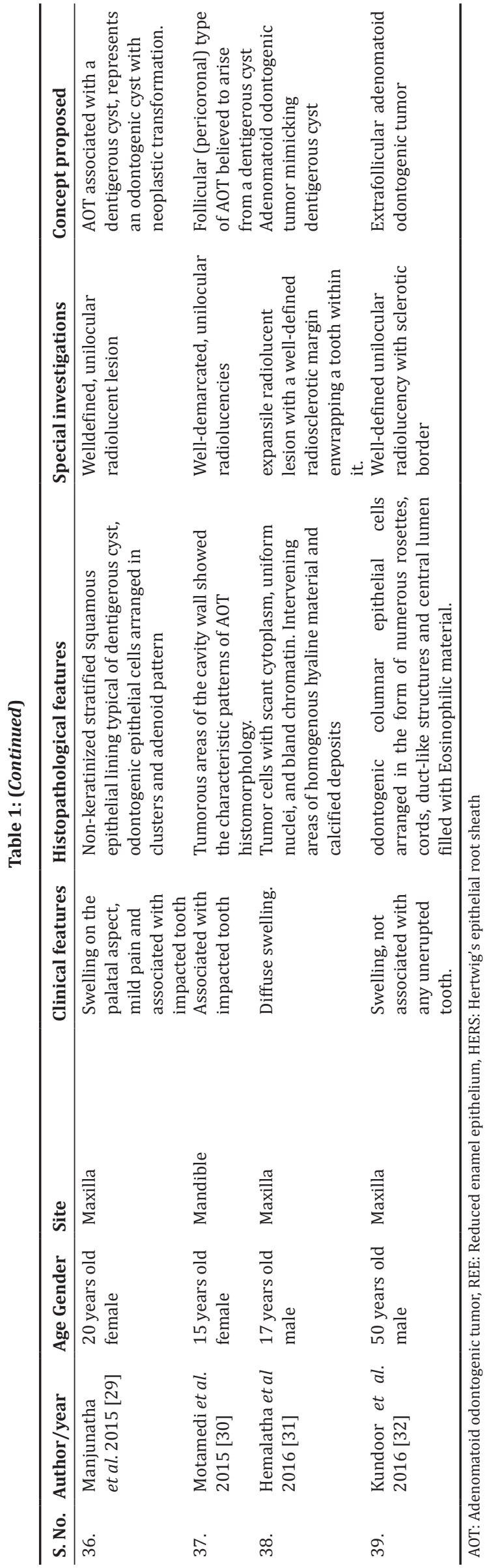

as a neoplastic growth of odontogenic epithelium. Glickman et al. drew an inference by saying that "such a controversy is irresolvable because sound arguments can be advanced in favor of and against both hypotheses. The arguments are based on personal bias rather than on scientific evidence" [8,57].

A molecular study by Razavi et al. showed that the Ki- 67 labeling index was lower in AOTs as compared to SMAs, signifying a hamartomatous nature [58]. However, using a human androgen receptor gene polymorphism assay, Gomes et al. found that AOTs are monoclonal and, therefore, neoplastic [59]. Certain characters or features of AOT which suggest it to be true neoplasm or hamartoma as stated by various authors

\section{Neoplasm}

Small size and probable early detection and it's removable before this slow-growing neoplasm reach considerable size [9]. Microscopic features show the greater difference from normal odontogenic apparatus than would have seen in a developmental anomaly [54]. It has been stated that many cases have gone undetected and untreated for many years due to their size and ultimately resulted in facial asymmetry and distortion. Using a human androgen receptor gene polymorphism assay, Gomes et al. found that AOTs are monoclonal and, therefore, neoplastic [60-63].

\section{Hamartoma}

In 2004, Rick stated that the limited size of AOT, its minimal growth potential, and the lack of recurrence even after incomplete removal attributed to its hamartomatous nature [6]. Low expression of BCL2 and Ki67 activity compared to ameloblastoma [58]. Medeiros et al. in 2005 conducted a study where they used proliferating cell nuclear antigen (marker for mitosis activity) and P53 (marker that indicates proliferative and anti-apoptotic activities) in AOT cases and found that IHC markers were very low thus they stated AOT as hamartoma rather than tumor $[58,64]$

\section{Histogenesis of AOT}

The origin of AOT is from the odontogenic epithelium; this fact is well established; however, the progenitor cell or tissue is not yet settled and still under discussion. The suggested cells by various authors are enamel organ [65,66], reduced enamel epithelium (REE) [67], undifferentiated odontogenic epithelium or stratum intermedium cells [68], stratum intermedium cells [69,70], and dental lamina and its remains (Philipsen and Reichart, 1999, Philipsen et al., 1992) [15].

Electron microscopic studies of duct-like structures formed within the tumor revealed the presence of hemidesmosomal junctions and evidence of basal lamina at the luminal pole of these cells. They also show secretory granules and coated vesicles near the luminal pole which are suggestive of a morphology similar to pre-ameloblasts. The eosinophilic material coexpressed basement membrane extracellular matrix proteins such as laminin, type IV collagen, heparin sulfate proteoglycan, fibronectin, and also enamel matrix proteins [71,72]. Furthermore, these cells are negative reactivity of these cells to lactoferrin and a1-antichymotrypsin anti-bodies which rule out glandular origin [14].

The non-duct-forming columnar cells expressed amelogenin reactivity, whereas the duct-forming cells showed no reactivity to amelogenin [71] or the other enamel matrix protein (enamelin and sheathlin) antibodies [73-75]. The ultrastructural studies show that the small, irregular calcifications may be partially composed of atypical enamel is supported by its positive reactivity to amelogenin, enamelin, and enamelysin although it is indistinguishable from calcified amyloid [76].

The epithelial tumor cells display features that are consistent with neoplastic (pre)ameloblasts in a state of arrested development [77]. The ameloblasts are yet metabolically active enough to produce basement membrane and enamel matrix proteins [78]. It is theorized 
that the accumulation and subsequent degradation of these enamel secretory products by enzymes such as enamelysin are responsible for the development of the duct-like structures [71]. These structures are in fact enclosed spherical microcysts and their nature whether completely intraepithelial or stromal is debatable [79].

The tumor may be partly cystic, and in some cases, the solid lesion may be present only as masses in the wall of a large cyst. It is generally believed that the lesion is not a neoplasm $[80,81]$.

Although the definition states that the lesion may have a cystic nature, very few case reports have described the cystic lining. Cystic presentation of AOT has been reported way back in 1915 by Harbitz who reported the lesion as "cystic adamantoma" [82].

Philipsen et al. have strongly argued in favor of the concept of AOT being derived from the complex system of the dental lamina or its remnants [11]. Marx and Stern considered AOT as a cyst and not a tumor and further gave a new terminology for this lesion, "adenomatoid odontogenic cyst (AOC)." Marx and Stern proposed that AOTs should not be considered tumors but cysts with a hamartomatous intraluminal proliferation of epithelial cells derived from the Hertwig's epithelial r1ot sheath (HERS) [9]. However, Rick stated that AOTs were benign embryonal neoplasms; he disagreed with the change in terminology as the majority of lesions have a predominantly solid component instead of a fluid-filled cavity. According to Marx and Stern, the AOC does not arise from the follicle of the tooth crown but instead arises from HERS, which would explain the finding of the tooth being completely within the lumen rather than the tooth root being within a bony crypt.

Considering all the case reports of AOT associated with dentigerous cyst, it is very much evident that the tumor is originating from the cystic lining. Moreover, the WHO definition of AOT given by Philipsen et al. supports this fact of cystic lining to be the progenitor for tumor in many cases. Since the origin of the cystic lining in the dentigerous cyst is REE and not the dental lamina, we propose the former to be the progenitor of AOT.

IHC, it has been shown that the immunophenotypic profile of REE and AOT epithelium is virtually identical [83]. The expression of CK14 and the ultrastructural aspects of the AOT probably indicated its origin in the reduced dental epithelium [83]. Where CK14 showed expression in the cells which were between the spindled and ductlike structures, these structures formed a cell group comparable to post-secretory ameloblasts of the REE, which was surrounded by a second group, composed of flat fusiform cells, which was similar to that of stellate reticulum. This justifies the expression in all epithelial cell elements of other AOTs and the REE, regardless of the histological characteristics [15]. Laminin was clearly present in the luminal surface of the adenomatoid structures and the lighter eosinophilic intercellular deposits, either focal or linear, which is compatible with the surface of the REE during the protective stage of amelogenesis. Nevertheless, the authors believed that some cells of AOT (cribriform areas) would resemble dental lamina (primitive cell), while others would represent histodifferentially more mature secretory phase of odontogenesis [15].

\section{CONCLUSION}

In classical AOT (solid), the proliferation of nodules originating from the cystic lining fills up the entire lumen whereas in cystic variant this process is incomplete and is thus seen only in parts of the cystic lining. Since the origin of the cystic lining is similar to a REE and not the dental lamina, we propose the former to be the progenitor of AOT. Furthermore, we consider extra-follicular, as well as peripheral AOTs, originate from the remnants of HERS (epithelial rests of Malassez), which complies with the common histology for all these variants [28]

\section{AUTHOR'S CONTRIBUTION}

Sahanaz P Ahmed: Compiled full literature search and drafted the manuscript. Arulmozhi Nandakumar: Developed the standards of manuscript. Ramya Ramadas: Supervised the manuscript making, and edited the manuscript. Karunya Krishnakumar: Provided guidance in the preparation of the manuscript.

\section{CONFLICTS OF INTEREST}

Authors declare that they have no conflicts of interest.

\section{REFERENCES}

1. Rajendran R. Shafer's Textbook of Oral Pathology. New Delhi: Elsevier India; 2009.

2. Kumamoto H. Molecular pathology of odontogenic tumors. J Oral Pathol Med 2006:35:65-74

3. Neville BW, Damm DD, Chi AC, Allen CM. Oral and Maxillofacial Pathology. UK: Elsevier Health Sciences; 2015.

4. Garg K, Chandra S, Raj V, Fareed W, Zafar M. Molecular and genetic aspects of odontogenic tumors: A review. Iran J Basic Med Sci 2015; 18:529-36.

5. Thompson L. World health organization classification of tumours: Pathology and genetics of head and neck tumours. Ear Nose Throat J 2006;85:74.

6. Philipsen HP, Reichart PA. Adenomatoid odontogenic tumour: Facts and figures. Oral Oncol 1999;35:125-31.

7. Lee SK, Kim YS. Current concepts and occurrence of epithelial odontogenic tumors: I. Ameloblastoma and adenomatoid odontogenic tumor. Korean J Pathol 2013;47:191-202.

8. Garg D, Palaskar S, Shetty VP, Bhushan A. Adenomatoid odontogenic tumor - Hamartoma or true neoplasm: A case report. J Oral Sci 2009;51:155-9.

9. Marx RE, Stern D. Oral and Maxillofacial Pathology. Chicago: Quintessence; 2003.

10. Vera Sempere FJ, Artes Martínez MJ, Vera Sirera B, Bonet Marco J. Follicular adenomatoid odontogenic tumor: Immunohistochemical study. Med Oral Patol Oral Cir Bucal 2006;11:E305-8.

11. Philipsen HP, Samman N, Ormiston IW, Wu PC, Reichart PA. Variants of the adenomatoid odontogenic tumor with a note on tumor origin. $\mathrm{J}$ Oral Pathol Med 1992;21:348-52.

12. Cawson RA, Binnie WH, Speight PM, Barrett AW, Wright JM. Lucas's Pathology of Tumors of the Oral Tissues. New York: Churchill Livingstone; 1998.

13. Domingues MG, Jaeger MM, Araújo VC, Araújo NS. Expression of cytokeratins in human enamel organ. Eur J Oral Sci 2000;108:43-7.

14. Takahashi H, Fujita S, Shibata Y, Yamaguchi A. Adenomatoid odontogenic tumour: Immunohistochemical demonstration of transferrin, ferritin and alpha-one-antitrypsin. J Oral Pathol Med 2001;30:237-44.

15. Crivelini MM, Soubhia AM, Felipini RC. Study on the origin and nature of the adenomatoid odontogenic tumor by immunohistochemistry. J Appl Oral Sci 2005; 13:406-12.

16. Madiyal A, Ajila V, Hegde S, Babu S. Clinical and radiographic features of adenomatoid odontogenic tumour. Acta Stomatol Naissi 2016;32:1595-610.

17. Mohanty N, Routray S, Swain N, Ingale Y. Adenomatoid odontogenic tumor with clear cell changes. Indian J Pathol Microbiol 2014;57:290-3.

18. Friedrich RE, Scheuer HA, Zustin J. Adenomatoid odontogenic tumor (AOT) of maxillary sinus: Case report with respect to immunohistochemical findings. In vivo 2009;23:111-6.

19. Yilmaz N, Acikgoz A, Celebi N, Zengin AZ, Gunhan O. Extrafollicular adenomatoid odontogenic tumor of the mandible: Report of a case. Eur J Dent 2009;3:71-4.

20. Bhandari N, Kothari M. Adenomatoid odontogenic tumour mimicking a periapical cyst in pregnant woman. Singapore Dent J 2010;31:26-9.

21. Phillips MD, Closmann JJ, Baus MR, Torske KR, Williams SB. Hybrid odontogenic tumor with features of ameloblastic fibro-odontoma, calcifying odontogenic cyst, and adenomatoid odontogenic tumor: A case report and review of the literature. J Oral Maxillofac Surg 2010;68:470-4.

22. Avinash Tejasvi ML, Prashanth Shenai K, Chatra L. Atypical case of periapical adenomatoid odontogenic tumour. J Maxillofac Oral Surg 2010;9:99-101.

23. Soares EC, Costa FW, Neto IC, Bezerra TP, Patrocínio RM, Alves AP. Rare hybrid odontogenic tumor in a 2-year-old child. J Craniofac Surg $2011 ; 22 \cdot 554-8$

24. Laheji A, Sakharde S, Chidambaram S, Gondhalekar RR, Shankar U, Radhika A. Adenoameloblastoma: A dilemma in diagnosis. J Contemp 
Dent Pr 2012;13:925-9.

25. Prakasam M, Tiwari S, Satpathy M, Banda VR. Adenomatoid odontogenic tumour. BMJ Case Rep 2013;2013:1-4.

26. Rathod V, Saluja S, Gondhalekar R, Pundir S, Dixit S, Agrawal S. Hybrid odontogenic lesion of the mandible: A rare case report with literature review. Int J Oral Med Sci 2014;12:245-50.

27. Bonardi JP, da Costa FH, Matheus RA, Ito FA, Pereira-Stabile CL. Rare presentation of adenomatoid odontogenic tumor in a pediatric patient: A case report. Oral Maxillofac Surg 2016;20:215-7.

28. Grover S, Mujib A, Rahim B, Parakkat NK, Kapoor S, Mittal K, et al. Case report cystic adenomatoid odontogenic tumor. Case Rep Dent 2015;2015:2-7.

29. Manjunatha BS, Harsh A, Purohit S, Naga MV. Adenomatoid odontogenic tumor associated with a dentigerous cyst. J Cancer Res Ther 2015;11:649.

30. Kumar R, Hashmi GS, Amjad SM, Ansari MK. Adenomatoid odontogenic cyst of mandible: A rare case report. Int J Heal Sci Res 2015;5:490-4.

31. Hemalatha AL, Shobha SN, Raghuveer CR, Sahni S, Kumari A. Adenomatoid odontogenic tumor : A dentigerous cyst mimic in maxilla. Int J Sci Study 2016;3:174-6.

32. Kundoor VK, Maloth KN, Guguloth NN, Kesidi S. Extrafollicular adenomatoid odontogenic tumor: An unusual case presentation. J Dent 2016;17:370-4.

33. Siwach P, Joy T, Tupkari J, Thakur A. Controversies in odontogenic tumours: Review. Sultan Qaboos Univ Med J 2017;17:e268-e276.

34. Philipsen HP, Birn H. The adenomatoid odontogenic tumour. Ameloblastic adenomatoid tumour or adeno-ameloblastoma. Acta Pathol Microbiol Scand 1969;75:375-98.

35. Batra BP. Adenomatoid odontogenic tumour: Review and case report. J Can Dent Assoc 2005;71:250-3.

36. Handschel JG, Depprich RA, Zimmermann AC, Braunstein S, Kübler NR. Adenomatoid odontogenic tumor of the mandible: Review of the literature and report of a rare case. Head Face Med 2005;1:3.

37. Motamedi MH, Shafeie HA, Azizi T. Salvage of an impacted canine associated with an adenomatoid odontogenic tumour: A case report. $\mathrm{Br}$ Dent J 2005;199:89-90.

38. Nigam S, Gupta SK, Chaturvedi KU. Adenomatoid odontogenic tumor - a rare cause of jaw swelling. Braz Dent J 2005;16:251-3.

39. Vargas PA, Carlos-Bregni R, Mosqueda-Taylor A, Cuairan-Ruidíaz V, Lopes MA, de Almeida OP, et al. Adenomatoid dentinoma or adenomatoid odontogenic hamartoma: What is the better term to denominate this uncommon odontogenic lesion? Oral Dis 2006; $12: 200-3$

40. Vera Sempere FJ, Artes Martínez MJ, Vera Sirera B, Bonet Marco J. Follicular adenomatoid odontogenic tumor: Immunohistochemical study. Med Oral Patol Oral Cir Bucal 2006;11:E305-8.

41. Nonaka CF, de Souza LB, Quinderé LB. Adenomatoid odontogenic tumour associated with dentigerous cyst - unusual case report. Braz J Otorhinolaryngol 2007;73:129-31.

42. Jivan V, Altini M, Meer S, Mahomed F. Adenomatoid odontogenic tumor (AOT) originating in a unicystic ameloblastoma: A case report. Head Neck Pathol 2007;1:146-9.

43. Santos JN, Lima FO, Romério P, Souza VF. Adenomatoid odontogenic tumor: An unusual case exhibiting cribriform aspect. Quintessence Int 2008;39:777-81.

44. Kemp S, Gallagher G, Kabani S, Todd R. Adenomatoid dentinoma: Case report and review of a rare odontogenic lesion. J Oral Maxillofac Surg 2008;66:1489-91

45. Carlos-Bregni R, Vargas PA, Silva AR, de Miranda Chaves-Netto HD, de Moraes M, Lopes MA. Adenomatoid odontogenic hamartoma: Concerns about correct nomenclature and 2 additional case reports. J Oral Maxillofac Surg 2009;67:1779-80.

46. Ide F. Inter-radicular adenomatoid odontogenic tumor of the anterior mandible. J Oral Maxillofac Surg 2010;68:490-1.

47. Martínez A, Mosqueda-Taylor A, Marchesani FJ, Brethauer U, Spencer ML. Adenomatoid odontogenic tumor concomitant with cystic complex odontoma: Case report. Oral Surg Oral Med Oral Pathol Oral Radiol Endod 2009;108:e25-9.

48. Sekiya R, Yamazaki H, Izawa K, Kaneko A, Tsukinoki K. Case of adenomatid odontogenic tumor during pregnancy. Tokai J Exp Clin Med 2011;36:124-7.

49. Agarwal A, Giri KY, Alam S. The interrelationship of adenomatoid odontogenic tumour and dentigerous cyst: A report of a rare case and review of the literature. Case Rep Pathol 2012;2012:358609.

50. Li BB, Xie XY, Jia SN. Adenomatoid odontogenic tumor with fibro-osseous reaction in the surrounding tissue. J Craniofac Surg 2013;24:e100-1.

51. Gomez RS, Castro WH, Gomes CC, Loyola AM. Adenomatoid odontogenic tumor associated with odontoma: A case report and critical review of the literature. Head Face Med 2013;9:20

52. Philipsen HP, Reichart PA. The adenomatoid odontogenic tumour: Ultrastructure of tumour cells and non-calcified amorphous masses. J Oral Pathol Med 1996;25:491-6.

53. Wright JM, Odell EW, Speight PM, Takata T. Odontogenic tumors, WHO 2005: Where do we go from here? Head Neck Pathol 2014;8:373-82.

54. Rick GM. Adenomatoid odontogenic tumor. Oral Maxillofac Surg Clin North Am 2004; 16:333-54.

55. Morgan PR. Odontogenic tumors: A review. Periodontol 2000 2011;57:160-76.

56. Poulson TC, Greer RO Jr. Adenomatoid odontogenic tumor: Clinicopathologic and ultrastructural concepts. J Oral Maxillofac Surg 1983;41:818-24.

57. Philipsen HP, Reichart PA, Zhang KH, Nikai H, Yu QX. Adenomatoid odontogenic tumor: Biologic profile based on 499 cases. J Oral Pathol Med 1991;20:149-58.

58. Razavi SM, Tabatabaie SH, Hoseini AT, Hoseini ET, Khabazian A. A comparative immunohistochemical study of ki-67 and bcl-2 expression in solid ameloblastoma and adenomatoid odontogenic tumor. Dent Res J (Isfahan) 2012;9:192-7

59. Gomes CC, da Silveira Oliveira C, Castro WH, De Lacerda JC, Gomez RS. Clonal nature of odontogenic tumours. J Oral Pathol Med 2009;38:397-400.

60. Lee JK, Lee KB, Hwang BN. Adenomatoid odontogenic tumor: A case report. J Oral Maxillofac Surg 2000;58:1161-4.

61. Raubenheimer EJ, Seeliger JE, van Heerden WF, Dreyer AF. Adenomatoid odontogenic tumour: A report of two large lesions. Dentomaxillofac Radiol 1991;20:43-5.

62. Shetty K, Vastardis S, Giannini P. Management of an unusually large adenomatoid odontogenic tumor. Oral Oncol Extra 2005;41:316-8.

63. Awange DO.Adenomatoid odontogenic tumour (adenoameloblastoma)a review. East Afr Med J 1991;68:155-63.

64. de Medeiros AM, Nonaka CF, Galvão HC, de Souza LB, Freitas Rde A. Expression of extracellular matrix proteins in ameloblastomas and adenomatoid odontogenic tumors. Eur Arch Otorhinolaryngol 2010;267:303-10.

65. Hatakeyama S, Suzuki A. Ultrastructural study of adenomatoid odontogenic tumor. J Oral Pathol Med 1978;7:295-310.

66. Schlosnagle DC, Someren A. The ultrastructure of the adenomatoid odontogenic tumor. Oral Surg Oral Med Oral Pathol 1981;52:154-61.

67. Courtney RM, Kerr DA. The odontogenic adenomatoid tumor. A comprehensive study of twenty new cases. Oral Surg Oral Med Oral Pathol 1975;39:424-35.

68. Tatemoto Y, Tanaka T, Okada Y, Mori M. Adenomatoid odontogenic tumour: Co-expression of keratin and vimentin. Virchows Arch A Pathol Anat Histopathol 1988;413:341-7.

69. Okada Y, Mochizuki K, Sugimura M, Noda Y, Mori M. Odontogenic tumor with combined characteristics of adenomatoid odontogenic and calcifying epithelial odontogenic tumors. Pathol Res Pract 1987;182:647-57.

70. Montes Ledesma C, Mosqueda Taylor A, Romero de León E, de la Piedra Garza M, Goldberg Jaukin P, Portilla Robertson J, et al. Adenomatoid odontogenic tumour with features of calcifying epithelial odontogenic tumour. (The so-called combined epithelial odontogenic tumour.) clinico-pathological report of 12 cases. Eur J Cancer B Oral Oncol 1993;29B:221-4.

71. Murata M, Cheng J, Horino K, Hara K, Shimokawa H, Saku T. Enamel proteins and extracellular matrix molecules are co-localized in the pseudocystic stromal space of adenomatoid odontogenic tumor. J oral Pathol Med 2000;29:483-90.

72. Nagatsuka H, Siar C, Nakano K, Tsujigiwa H. Differential expression of collagen IV $\alpha 1$ to $\alpha 6$ chains in basement membranes of benign and malignant odontogenic tumors. Virchows Arch 2002;441:392-9.

73. Mori M, Yamada K, Kasai T, Yamada T, Shimokawa H, Sasaki S, et al. Immunohistochemical expression of amelogenins in odontogenic epithelial tumours and cysts. Virchows Arch A Pathol Anat Histopathol 1991;418:319-25.

74. Mori M, Yamada T, Doi T, Ohmura H, Takai Y, Shrestha P, et al. Expression of tenascin in odontogenic tumours. Eur J Cancer B Oral Oncol 1995;31B:275-9.

75. Saku T, Okabe H, Shimokawa H. Immunohistochemical demonstration of enamel proteins in odontogenic tumors. J Oral Pathol Med 1992;21:113-9. 
76. El-Labban NG. The nature of the eosinophilic and laminated masses in the adenomatoid odontogenic tumor: A histochemical and ultrastructural study. J Oral Pathol Med 1992;21:75-81.

77. Yamamoto H, Kozawa Y, Hirai G, Hagiwara T, Nakamura T. Adenomatoid odontogenic tumor: Light and electron microscopic study. Int J Oral Surg 1981;10:272-8

78. Nanci A. Ten Cate's Oral Histology-E-Book: Development, Structure, and Function. UK: Elsevier Health Sciences; 2017.

79. do Carmo MA, Silva EC. Argyrophilic nucleolar organizer regions (AgNORs) in ameloblastomas and adenomatoid odontogenic tumours
(AOTs). J Oral Pathol Med 1998;27:153-6.

80. Kramer IRH, Pindborg JJ, Shear M. Histological Typing of Odontogenic Tumours. New York: Springer Science and Business Media; 1992.

81. Gadewar DR, Srikant N. Adenomatoid odontogenic tumour: Tumour or a cyst, a histopathological support for the controversy. Int J Pediatr Otorhinolaryngol 2010;74:333-7.

82. Harbitz F. On cystic tumors of the maxilla, and especially on adamantine cystadenomas (adamantomas). Dent Cosm 1915;57:1081-93.

83. Crivelini MM, de Araújo VC, de Sousa SO, de Araújo NS. Cytokeratins in epithelia of odontogenic neoplasms. Oral Dis 2003;9:1-6. 